\title{
PATERNALISMO INDUSTRIAL Y DISCIPLINAMIENTO CULTURAL EN EL MUNDO FESTIVO DE LAS CIUDADES CARBONIFERAS CHILENAS: LOTA, 1920-1950*
}

\author{
INDUSTRIAL PATERNALISM AND CULTURAL DISCIPLINING \\ IN THE FESTIVE WORLD OF THE CHILEAN COAL-MINING \\ TOWNS: LOTA, 1920-1950
}

\section{MILTON GODOY ORELLANA**}

\section{RESUMEN}

El artículo analiza el proceso de disciplinamiento cultural suscitado en la ciudad carbonífera de Lota en el contexto de las políticas de paternalismo industrial manadas desde el departamento de bienestar de la Compañía Carbonífera de Lota. Para el efecto se estudia el control de las fiestas desenfrenadas con consumo de alcohol y los estímulos entregados a la celebración sobria y cívica de las Fiestas Patrias como momentos de celebración que aunaban a la comunidad, integrándola en la idea de patriotismo y compromiso de trabajo que redundaría en el bienestar para los trabajadores y la empresa.

Palabras clave: Paternalismo industrial, disciplinamiento cultural, fiesta, Lota.

\section{ABSTRACT}

This article analyzes the cultural disciplining process that took place in the coal mining town of Lota in the context of the industrial paternalism policies emerged from the Lota Coal Company's welfare department. For this purpose, we study the control over

* Este trabajo ha sido financiado por el Fondo de Ciencia y Tecnología mediante el Proyecto FONDECYT N ${ }^{\circ} 1120449$.

${ }^{*}$ Doctor en Historia. Investigador Asociado en el Instituto de Estudios Internacionales (INTE) de la Universidad Arturo Prat. Docente en la Universidad Academia de Humanismo Cristiano. Mis agradecimientos a Hernán Venegas, Enzo Videla, Carolina Valenzuela y Marco Murua, quienes contribuyeron de diversas maneras a la realización de este trabajo, aunque la responsabilidad final me pertenece. Email: mgodoy@academia.cl;milgodoy@uchile.cl 
parties where alcohol consumption was unrestricted and stimuli awarded for sober and civic celebration of the National Independence Holidays as moments that united the community, integrating it to the idea of patriotism and work commitment that would result in the wellbeing of the workers and the company.

Keywords: Industrial paternalism, cultural disciplining, parties, Lota.

Recibido: 10.06.14. Aceptado: 22.12.14.

\footnotetext{
"El sargento Zulemo se acercó una tarde al Feo en la esquina de la cancha de rayuela y le advirtió que se anduviera con cuidado: los del Departamento de Bienestar lo estaban vigilando $[\ldots]$.

Te puede costar la pega Feíto, le dijo".

Hernán Rivera Letelier, Historia de amor con hombre bailando, 2013.
}

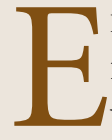
L DIÁLOGO PRESENTADO como epígrafe de este artículo es resultado de la ficción novelesca de Rivera Letelier. No obstante, contiene elementos vivenciales y autobiográficos (Rivera Letelier, en García 2013), que soportan importantes sustratos de veracidad. De esta manera, es posible observar cómo los interlocutores del episodio entre el sargento y el personaje principal logran perfilar sintéticamente algunas de las funciones menos conocidas de los Departamentos de Bienestar al interior de las ciudades mineras denominadas como Company Town -o, algunas de sus múltiples variantes idiomáticas para designar un similar fenómeno ${ }^{1}-$ que resultaban de los diseños de control social, implementados a partir de las nuevas formas de patronato industrial emergidas en Chile, y puntualmente en Lota, después de 1930. En efecto, las palabras del sargento de Carabineros al personaje central evidencian tres cosas que en los poblados de la empresas mineras fueron gravitantes: en primer lugar, la policía -al igual que otras agencias del Estado como la escuela y los profesores- estaba supeditada a los designios empresariales vía Departamento de Bienestar; segundo, las funciones de esta institución contemplaban el control interno mediante el registro de la conducta de los trabajadores, destacando la función disciplinante del departamento que se traducía en la vigilancia por parte de funcionarios de seguridad, donde además operaba el estímulo a la delación

${ }^{1}$ En Alemania se denominaba el Arbeiten Siedlungen (asentamiento de trabajo); en Francia, la Cité Ouvriere; en Inglaterra se conocía como el Industrial Village; mientras que en España se llamó la Colonia Industrial; finalmente, en Estados Unidos se le denominó el Company Town. 
de quienes infringieran las normas internas; en tercer lugar, la sanción a los infractores de las normativas internas significaban castigos tales como el cambio de lugar de faena en la empresa o, definitivamente, la pérdida del trabajo y con ello la expulsión de la casa que se le facilitaba al obrero, exponiéndolo a vagar en busca de una nueva faena con el estigma del despido, cuando no a trasladarse a la marginalidad de las ciudades -en el decir de Walter Benjamin (2011, p. 90)- "a los cuarteles de la pobreza, los desperdigados asilos de la miseria".

El análisis del paternalismo industrial como un conjunto de estrategias de control social que hacía de la empresa un ente que articulaba los más ínfimos espacios de la vida social de los obreros se ha centrado en temas como la salud, deporte, vivienda y condiciones de vida, soslayando el universo festivo, desarrollado al interior de los espacios dominados por la empresa y la necesidad de disciplinar un conjunto de prácticas populares en torno a la fiesta que minaban la posibilidad de implementación efectiva de políticas paternalistas, una temática de gran importancia y alcance que requiere ser abordada.

¿Cómo se relacionan estos dos conceptos en este proceso histórico desarrollado entre 1920 y 1950? En primer lugar, ambos apelan a formas de intervención y control social. En efecto, el patrimonio industrial lo hace principalmente mediante concesiones y premios, como reconocimientos acotados a quienes cumplían con la normativa estructurada por la empresa e implementada al interior de la denominada "ciudadela modelo", planteando directrices en el comportamiento e intentando influir en el obrero, tanto a nivel de su familia como de su sociabilidad.

Si bien es cierto, existen diferentes manifestaciones del paternalismo, que consideran desde los extremos del denominado "feudalismo industrial" que, según Michel Labori y Jean Marc Tetier, se caracterizaba por la existencia de un acuerdo entre el patrón y los obreros, presencia de organismos educativos y de caridad, conjunto de elementos que al sumarle el control de la vida política y de los medios permitía concretar el esquema paternalista y completar un sistema que posibilitaba "encuadrar la mano de obra desde el nacimiento a la muerte, en la fábrica, en su cotidianeidad, en sus recreaciones", donde no existe una opresión directa, sino "una forma de dominación más solapada, más insidiosa y mejor adaptada al contexto local" (Labori y Tetier, 1995, pp. 42-43), como aconteció hacia fines del siglo XIX en la localidad de Fourmies, en el sur de Francia.

No obstante, el concepto de paternalismo fue bastante dinámico desde fines del siglo XIX, como el caso presentado con antelación, hasta el pe- 
riodo en que se centra el presente estudio. En efecto, Philip Scranton ha planteado que el paternalismo puede explicarse en función de la extensión de la autoridad patriarcal en la granja, el taller o la fábrica, configurando un accionar que aparece representado como una reconstitución de la dominación del padre, expresado simbólicamente sobre un conjunto de obreros-niños (1984, pp. 235-236). Esta ha sido una realidad constatable en diversas realidades haciendo comparable, por ejemplo, el caso de Lota con Barruelo de Santullan, debido a que en ambos casos se busca modelar el entorno y sus habitantes para generar una sociedad alejada del conflicto social y bajo sujeción de los intereses productivos de los dueños (Cuevas, 2006). Este conjunto de controles, en los más diversos niveles, ha permitido a José Sierra Álvarez proponer la idea del "obrero soñado", que buscaba el disciplinamiento de sus operarios, tanto en sus espacios como en los tiempos de asueto (1990).

En este contexto conceptual, el disciplinamiento opera como complemento del paternalismo, en tanto es una forma de control de las personas, tanto en el espacio intra como extramuros (Venegas, 2013). En el decir de Foucault el disciplinamiento se entiende como un táctica de poder, basada en una triada de criterios que busca que los efectos del poder social, su máxima expresión e intensidad, extendiéndose "lo más lejos posible, sin fracaso ni laguna; ligar en fin este crecimiento económico del poder y el rendimiento de los aparatos en el interior de los cuales se ejerce, en suma aumentar a la vez la docilidad y la utilidad de todos los elementos del sistema" (1989, p. 221).

En virtud de lo anterior es dable pensar que en el ámbito de las expresiones culturales y sociales que se necesita replantear, como un proceso de transformación de la sociedad, debemos incluir las transformaciones que redundan en el espacio público, la sacralización del trabajo, las manifestaciones festivas civilizadas, una nueva concepción del placer y el juego, en definitiva como escribió José Pedro Barrán, una "privatización de las emociones" (1990).

En otra dimensión del problema es posible constatar que ambos conceptos contienen en sí una variable que considera la expresión laboral y económica del problema, que se expresa como fin último de las concepciones empresariales de la productividad y eficiencia manifestada en la optimización de las horas de trabajo para producir más a un costo menor.

No obstante, como antes señalaba, existe un punto de encuentro y de fusión entre ambos conceptos, en tanto tienen como fin último controlar o morigerar las conductas sociales más rupturistas que se confrontaban con 
las ideas de progreso, urbanidad y una nueva lógica laboral de asistencia al trabajo y respeto a los horarios, la "exactitud burguesa", a que refería Edward Thompson en uno de sus clásicos estudios (1984, p. 240). Es en este contexto que parece plausible, a la luz de los indicados conceptos, analizar el fenómeno festivo y sus controles para explicar el derrotero hacia el cual se encaminó el diseño de las festividades programadas y aceptadas por la compañía minera de Lota.

En aras de este objetivo de control de las fiestas y sociabilidad, la compañía minera de Lota no escatimó esfuerzos en intervenir el mundo festivo popular al interior de la ciudad, que estaba bajo la égida de la compañía, donde pretendía controlar los excesos, principalmente visualizados en el mundo popular, bajo el manto del bienestar obrero y sus familias -asunto que, probablemente, sí se suscitó-, en aras de sus propios intereses.

Precisamente, basándose en las ideas anteriores, es posible cerciorarse de que el fenómeno analizado se visibiliza y se hace molesto, cuando emerge en Lota un nuevo tipo de paternalismo que es posible de caracterizarse como "burocrático", e iniciado desde los primeros años de la década de los veinte en el siglo pasado, cuya consolidación e institucionalización está asociada a la implementación del Departamento de Bienestar de la compañía minera de Lota, dirigido desde su fundación en 1922 por Octavio Astorquiza, quien dejó este cargo en 1948, cubriendo el periodo de estudio del presente artículo.

El tipo de paternalismo resultante de esta nueva institución presenta una práctica diferente al que le antecedía, caracterizado por una relación patrón-obrero más directa, prevaleciendo la acción patronal que se plasmaba en concesiones cara a cara. El nuevo paternalismo estuvo definido por un trabajo de diseño del control que recaía en oficinas encargadas de tópicos diversos que intentaban abarcar la mayor amplitud de la vida del obrero, incluyendo las festividades y sociabilidad, en un claro proceso de disciplinamiento cultural.

La hipótesis de trabajo que sustenta esta investigación es pensar el patronato industrial y el disciplinamiento cultural como elementos complementarios para controlar la realidad festiva en la ciudadela ideal de Lota Alto. En efecto, si el Estado nacional chileno y sus agencias pudieron morigerar y controlar prácticas culturales festivas como el carnaval, erradicándolo o acotándolo en el espacio público; a la par de disminuir la multiplicidad de fiestas religiosas del Chile republicano temprano e imponer las festividades nacionales, como un mecanismo de conversión e integración a la nacionalidad (Godoy, 2009). Ergo, si esto fue posible en las principales ciudades y 
poblados del país -aunque con claras resistencias sociales de los sectores populares y de la sociedad en términos amplios- en sociedades abiertas y medianamente democráticas, es posible sustentar que en una microsociedad como la de los obreros de Lota Alto, expuestos a un importante nivel de control de la empresa carbonífera, este proceso fue más rápido y definido, con un claro énfasis en el cambio de la forma de la celebración impuesta desde la compañía con el fin último de transformación de los individuos, plasmado en el ideal del auto-control o, como señala Pedro Oliver, de la implantación de "un orden social autorregulado" (2005, pp. 78-79).

Es importante el énfasis en este punto, en tanto el presente artículo se encamina por la senda de estudiar los controles planteados al espacio festivo, desde la compañía a través de su Departamento de Bienestar, sin dejar de reconocer la alta potencialidad de mecanismos de descompresión social, en tanto funcionaban como una válvula de escape, que permitía unos días de disipación y desenfreno de los sectores subalternos (Scott, 2000), para retornar a la rutinaria dominación o de resistencia y rebelión que las fiestas y los juegos han representado en diversas sociedades a través de la historia (Berce, 1976; Hidalgo y Castro, 1999; Pérez, 2013).

\section{LOS CONTROLES DE LA “CIUDADELA INDUSTRIAL MODELO” (Astorquiza y Galleguillos, 1951)}

Lota fue una de las principales ciudades mineras de la región carbonífera de Concepción que contó con una serie de avances y urbanización que la diferenciaban de sus vecinas y fueron modelando una ciudadela cercada y delimitada, con ingreso y permanencia controlada, que generó una dinámica societal particular y característica que diferenciaba a Lota Alto de Lota Bajo por su ubicación al pie de la colina en que esta se situaba. Ubicada en la altura, la ciudadela se convirtió en un emplazamiento que contaba con una serie de elementos escasos en la mayoría de las ciudades chilenas del periodo, tales como Plazas de juegos infantiles, biógrafo, clubes obreros, centros sociales y deportivos, instalaciones de lavaderos y pabellones higiénicos, distribuidos en el espacio urbano que albergaba las viviendas del personal de la compañía, tanto a nivel de empleados como de obreros.

Hacia 1930, un periódico regional destacaba estas características calificando a Lota Alto de "enormemente diferente" al aspecto que presentaba la población de la parte baja y sus alrededores: 
Todo da la impresión de una ciudad nueva, de algo diferente, injertado en nuestras tierras por quién sabe qué milagros. La calle principal se abre con su pavimentación de primera clase, tan limpia como la de cualquier calle de Santiago, exornada de edificios de dos o tres pisos pintados de colores alegres, sobre los cuales se destacan manchas de flores suspendidas de los balcones y de las pequeñas azoteas. [...] Caminando a lo largo de cada una de ellas se advierte el mismo ambiente de comodidad y de buen gusto en los pabellones en que reside la gente trabajadora (El Sur, 1930, mayo 28).

Tal como en el ejemplo anterior, no fueron pocos los testigos que destacaron las características de unicidad que presentaba la ciudadela de Lota. El énfasis estaba puesto en la comodidad y condiciones de las viviendas ofrecidas a los obreros, especialmente en un momento de la historia de Chile en que era más fácil encontrar trabajo que una vivienda con alguna dignidad.

Estas prerrogativas -extrañas al conjunto de la realidad laboral chilenaconcedidas a los obreros de la empresa carbonífera eran parte de la política paternalista que desarrollaba la compañía, la que esencialmente estaba destinada a controlar la sociabilidad y los tiempos de los trabajadores, más allá de sus funciones al interior de la empresa, intentando abarcar -como ha señalado Sierra Álvarez- los espacios y tiempos de "no trabajo" (1990).

De esta manera, la empresa mediante el citado Departamento de Bienestar diseñó un entramado de control societal que regulaba la mayoría de las actividades realizadas por los trabajadores y sus familias en los tiempos de ocio o que no estaban dedicados a las labores productivas. Como antes indicaba, la idea central era erradicación -o al menos el control- de una sociabilidad popular que no era funcional a los intereses de la compañía.

La dura vida de los mineros, sometidos a un trabajo físico extenuante, con largas jornadas y expuestos a frecuentes accidentes que podían terminar con sus vidas o, en el mejor de los casos, dejarlos con heridas de diversas intensidades, hacen de la minería uno de los campos laborales donde los excesos constituyen un retrato negativo de la sociabilidad obrera, resumidos en calificativos como dilapidadores, mujeriegos y desordenados, las que mayoritariamente forman parte de una visión caricaturizada de esta realidad. No obstante, muchos de estos elementos se encuentran ligados a la identidad minera en un amplio espectro, especialmente el consumo de alcohol, que en los poblados mineros constituye un verdadero problema, resultando extremadamente difícil su control en un área productiva como 
la minería, donde su consumo ha sido recurrente en los más diversos espacios y tiempos (Absi, 2009, pp. 69-77).

Por tanto, al interior de la ciudadela de Lota la venta de alcohol estaba prohibida. El tema del consumo de alcohol fue permanentemente cuestionado en el contexto paternalista que inspiraba a los empresarios del carbón en Lota quienes diseñaron el cierre perimetral de la compañía con puertas custodiadas por guardias que evitaran el acceso de los elementos considerados nocivos para los trabajadores, tales como el alcohol y las prostitutas. De hecho, las explotaciones cercanas a Lota siguieron el ejemplo del cercado y control, planteándose la misma idea en Schwager, donde en 1923 se justificaba el cierre en ejecución, en tanto era útil "principalmente, para resguardar a los trabajadores del alcohol, vinos y aguardientes" (El Sur, 1923, agosto 7). A la par se desarrolló un eficaz control sobre los empleados con guardias de la empresa e informantes que delataban a los trabajadores por el consumo de alcohol o por su participación política. El control se materializaba en una carpeta individual que se denominaba "prontuario del trabajador", donde se consignaban todas las acciones del funcionario, las que incidirían al momento de la concesión de una casa, el ascenso o su despido. Un ejemplo se da en el caso de Segundo Monsalve, de quien el director del Departamento de Bienestar de la mina de Schwager solicitaba a su colega de la mina de Lota un informe acerca de "la conducta observada" por Monsalve (Empresa Nacional del Carbón, 1957, noviembre 28), quien probablemente, despedido de esta última mina, había llegado a buscar trabajo a Schwager y sobre el cual se entregaban hasta detalles de su vida privada.

Entre los aspectos que se consideraba en las anotaciones acerca del trabajador era la eventual propensión al consumo de alcohol. Como ejemplo, en el prontuario de Isaías Inostroza se incluía una carta manuscrita donde un informante consignaba que el día 6 de agosto de 1934 se había ido a beber con unos amigos a Lota Bajo "de donde llegaron a las 3 horas del día 7 en manifiesto estado de ebriedad y formaron un desorden junto a la oficina de la población" (Empresa Nacional del Carbón, 1934, abril 6). Inostroza era motivo de alta preocupación para las autoridades, porque además de acusarlo de bebedor, años después sería considerado un elemento nocivo para los trabajadores, pues era un "espía" (Empresa Nacional del Carbón, 1936, febrero 21) de la Federación Obrera de Chile y mantenía informado a los "subversivos" que trabajaban en la compañía (Ibídem). 


\section{ERRADICANDO LA VIDA LICENCIOSA Y LA FESTIVIDAD OCIOSA}

Fiesta y trabajo es un binomio excluyente, en tanto el tiempo de uno no es el del otro, funcionando en ámbitos diferentes. El día festivo es precisamente aquel que aleja de las tareas cotidianas, el asueto de lo trabajado, el tiempo festivo es esporádico, mientras que el tiempo laboral -en el sentido moderno- es permanente, cotidiano, estructurado, medido, cuantificado.

Cuando irrumpe esta nueva concepción de trabajo moderno, el discurso de la inconstancia laboral que caracterizó a los trabajadores en términos amplios y a los mineros de manera particular fue el centro de los cuestionamientos. Obviamente, también lo fue el tiempo destinado a la fiesta. Un ejemplo está dado hacia fines del siglo XIX a través del secretario de la legación francesa en Chile, quien envió un informe a París dando cuenta de la situación de las minas de Lota y sus trabajadores, destacando primero la "falta de brazos" -un lugar común en las críticas de la elite del periodo (Norambuena, 1997) - y, segundo, la baja producción y del dinero obtenido como remuneración mensual de los trabajadores debido a la inconstancia, índices que -según su opinión- podrían revertirse "trabajando a la europea, es decir, de una manera regular" (Ministerio de Asuntos Extranjeros de Francia, 1884). Precisamente, esta demanda de trabajar "a la europea" fue el leitmotiv de los empresarios carboníferos de Lota y las razones que explican la elección de los modelos productivos y de control de los trabajadores que aplicaron en sus explotaciones.

Frente a esta sempiterna realidad laboral y social de los trabajadores, ¿cuál fue la principal preocupación de los empresarios en torno al tema festivo? En primer lugar los intentos de disciplinamiento festivo estuvieron encaminados a disminuir el consumo de alcohol, partiendo por reemplazar las bebidas de más alta graduación, por algunas de menor contenido de alcohol, hasta llegar a excluirlas de los bailes y fiestas, reemplazándola por el consumo de bebidas gaseosas en las fiestas organizadas por el Departamento de Bienestar (El Sur, 1925, enero 27), directamente relacionado con la asistencia laboral, por la extensión de la juerga en los días siguientes a las celebraciones.

El problema principal, que preocupaba a los empresarios, era la disminución de la productividad, mas no la salud del obrero, en tanto se consideraba que cuando la demanda de carbón disminuía, el asunto carecía de importancia "pero sí la tiene, y muy grande, cuando las demandas aumentan y es preciso trabajar con toda energía y con todos los elementos posibles" (El Sur, 1930, mayo 21). 
La prohibición de la venta y consumo de alcohol estaba cruzada por un conjunto importante de intereses económicos que hacían las decisiones zigzagueantes respecto de las medidas tomadas. El peligro del alcoholismo y sus secuelas se intentó abordar de diversas maneras. El consumo de alcohol en largas jornadas nocturnas hacía que, en muchas ocasiones, los obreros se presentaran al trabajo en manifiesto estado de ebriedad, aumentando los accidentes al interior de las faenas, razón por la que se suprimió su venta para convertirlos por la abstención a la bebida en hombres de "plena conciencia, deseosos de prosperar, limpios, sanos de cuerpo y alma, jefes de familia honorables y amantes; en fin, haciendo del harapo humano que se arrastra por las calicheras inclementes del norte, en las minas y explotaciones de capitalistas chilenos o extranjeros, un ciudadano útil y un obrero eficiente" (El Sur, 1921, febrero 11).

No obstante, los caminos para el control variaron entre la prohibición absoluta, la permisión de su venta en ciertos días del año, la libertad para su expendio, con los impactos negativos que tenía acrecentando los índices de ausentismo laboral. En 1930 empezó a regir el permiso para su venta, provocando el ausentismo laboral después de los días festivos religiosos u oficiales, además de la práctica de "hacer San lunes" (Rodríguez, 1875, p. 289), convirtiendo la ausencia laboral posterior al descanso dominical en una verdadera institución laboral chilena, hasta avanzado el siglo XX. Al respecto, un periódico de la época señaló en relación a los trabajadores que "se ha podido notar que los días lunes dejan de concurrir a sus puestos en algunas minas", en un porcentaje que bordeaba el $30 \%$, que en el caso de la Compañía Carbonífera Schwager -vecina a la estudiada- significaba un ausentismo laboral de alrededor de mil trabajadores (El Sur, 1930, mayo 21).

En el caso de la Compañía Carbonífera e Industrial de Lota se trataba frecuentemente el tema del ausentismo laboral ligado a las fiestas o al consumo de alcohol. El medio preferido para socializar el problema era mediante notas y editoriales de La Opinión, su órgano oficial, resaltando el daño que hacían "los falleros" -como se denominaba a los ausentes- a la empresa y la comunidad, ya que al estar obligados a traer más personal los exponía a la carencia de habitaciones. En Lota, los índices más altos de inasistencias que se presentaban alcanzaban el 30\% del personal, siendo el promedio de un $15 \%$, en circunstancias que la compañía calculaba un $5 \%$ como máximo para su funcionamiento normal.

En segundo lugar, algunas fiestas se usaron como medios de formación cívica y de integración social en espacios de abstención del consumo de alcohol. En este sentido, la fiesta patria celebrada al interior de Lota cumplía 
múltiples objetivos: fusionar la sociedad local en un contexto de sana alegría, donde se cantaban loas al deber cívico, el saber y el trabajo, imbricado en una triada que cristalizaba en una concepción del patriotismo. Como se escribió en el periódico de la empresa:

Los pueblos que tienen una historia que respetar, una gloriosa herencia de tradiciones que recoger, tienen también un porvenir que asegurar; $y$ esta es la parte que nos corresponde a nosotros, contribuyendo al porvenir de nuestra Patria, con nuestras ideas, con nuestra palabra y con nuestro trabajo mismo. Trabajo, saber y patriotismo caerán como rosas perfumadas sobre el altar sagrado de la Patria, porque la gloria y la grandeza de Chile deberán ostentarse y basarse en el carácter y en el saber de sus hijos.

Para ser un hombre verdaderamente patriota es necesario que modele su carácter, abrazando en sí el deseo ardiente, noble y grande de servir a su Patria dignamente hasta convertirse en un héroe (La Opinión, 1928, 18 septiembre, p. 2).

En mayo de 1920 una noticia incluida en un periódico de la región aludía a la ausencia laboral provocada después de la celebración de la tradicional festividad de la Cruz de Mayo, destacando que los trabajadores de las Minas Schwager y Lota "no salieron ayer a sus faenas [...] hay que dejar constancia en la inasistencia de los operarios a las labores los días sábado y domingo que son conceptuados también como festivos" (El Sur, 1924, mayo 4). Como este, muchos casos de antigua data se repetían en el contexto de la sociabilidad minera, en lugares tan diversos como el norte cuprífero de Chile o en las fábricas rurales y urbanas de España, donde el ausentismo laboral tenía a las festividades religiosas como una de sus principales causas (López, 2010, p. 101). En Lota Alto el tema de las fiestas religiosas fue solucionado mediante la erección de una iglesia de estilo gótico, construida en mampostería de piedra (1928), asegurando la presencia permanente de un cura al interior de la ciudadela, quien, probablemente -como aconteció en otras realidades paternalistas- tenía incuestionables vínculos con la autoridad ${ }^{2}$.

Un problema mayor presentó la celebración del día de la patria, en tanto es una festividad de alcance nacional debido a que provoca una amplia movilización en las ciudades donde se celebra y requiere de un tiempo especial "vacío", un día feriado en que se posterga el trabajo (DaMatta, 2002,

${ }^{2}$ Por cierto, instituciones como Carabineros de Chile se relacionaban de manera similar con la Compañía de Lota que les entregó para su servicio un nuevo y moderno cuartel en julio de 1945, ver La Opinión. Lota Alto, julio de 1945, p. 1. 
p. 63). Entonces es dable preguntarse, ¿cómo logró la empresa carbonífera conciliar sus intereses con una celebración de profunda raigambre en la sociabilidad popular, la que además estaba estimulada por los intereses del Estado nacional?

La celebración del 18 de septiembre recibía los principales esfuerzos del Departamento de Bienestar, que preparaba con antelación las calles de la ciudad y adornaba la entrada de la población con arcos de flores y carteles con loas "a los Padres de la Patria" (ver Fig. 3 ) a la par de organizar la jornada de las fiestas patrias. En las primeras horas de la mañana del 18 de septiembre se izaba la bandera en la Tenencia de Carabineros con asistencia de los alumnos de las escuelas de la compañía minera, iniciándose el abanderamiento general de la población, mientras la banda de Lota Alto recorría las calles tocando marchas patrióticas. Más tarde se realizaba un acto patriótico organizado por la comisión oficial de las Fiestas Patrias de Lota Alto, donde el principal acto era cívico: las autoridades presentaban sus discursos y el jefe de la policía presentaba una "Conferencia patriótica", seguida por un desfile abierto por los representantes de Carabineros en el lugar y en el que participaban todas las escuelas, los Scouts, las instituciones sociales, etc. Ambos grupos lo hacían con la marcialidad del caso; primaba el orden, tanto de alumnos y policía como de los observadores que se agolpaban a lo largo de la calle principal de Lota Alto (ver Figs. 1 y 2).

La celebración contemplaba un torneo deportivo organizado por la Liga de Football de Lota, con premios ofrecidos por la Compañía, la Municipalidad y la liga, y en el cual tomaban parte los clubes deportivos financiados por la compañía. La celebración continuaba con un acto patriótico en el teatro con la participación de los alumnos de las escuelas "Matías Cousiño" e "Isidora Cousiño", luego una función del biógrafo en el teatro, ofrecida por la Compañía a las escuelas públicas, concurso y premiación de ejercicios para niños en la plaza de juegos infantiles de Lota Alto, biógrafo al aire libre, amenizado por la banda de músicos en la plazuela central, y una presentación de fuegos artificiales y elevación de globos en la plazuela, finalizando con una gala en el teatro, acompañada de la banda de jazz. Finalmente, el día 19 se repetía el mismo programa, terminando con una función en el teatro (El Sur, 1926, septiembre 16).

En la prensa regional y local $^{3}$ eran recurrentes las noticias relativas a la celebración del dieciocho, en que la empresa se vanagloriaba de la aplicación

\footnotetext{
${ }^{3}$ Para un ejemplo ver Oro Negro. Periódico Independiente al servicio de la zona carbonífera, 3 de septiembre de 1949; también en "Programa para la celebración de fiestas patrias", El Sur, 16 de septiembre de 1926.
} 
metódica del programa elaborado por la oficina de bienestar, resaltándose con encomio la conducta observada por los trabajadores durante los días patrios. Como escribió uno de estos periódicos respecto de la celebración de 1925, ésta "se llevó a efecto con todo orden y compostura, sin una nota discordante!” (El Sur, 1925, septiembre 25).

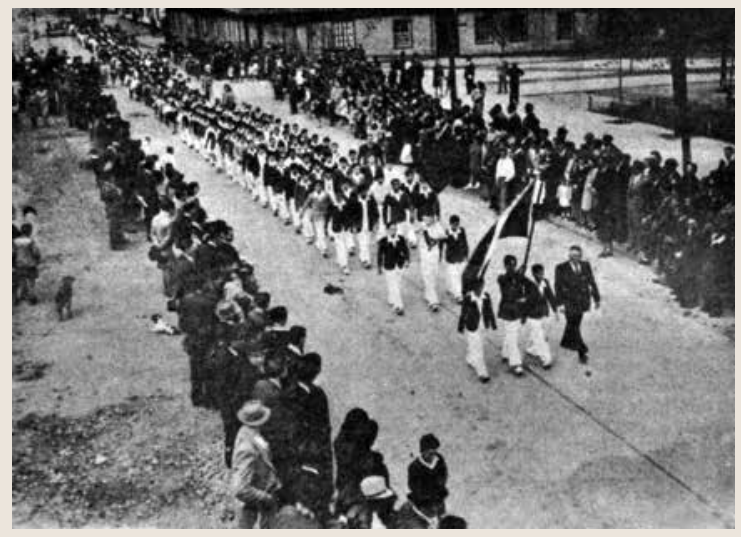

Figura 1. Desfile de la escuela "Matías Cousiño" (La Opinión, 1945, octubre, p. 5).

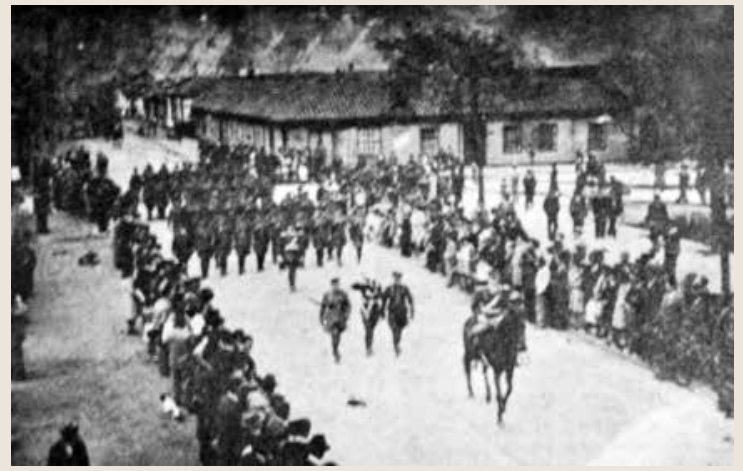

Figura 2. "Cuerpo de carabineros de Lota desfilando" (La Opinión, 1945, octubre, p. 5). 


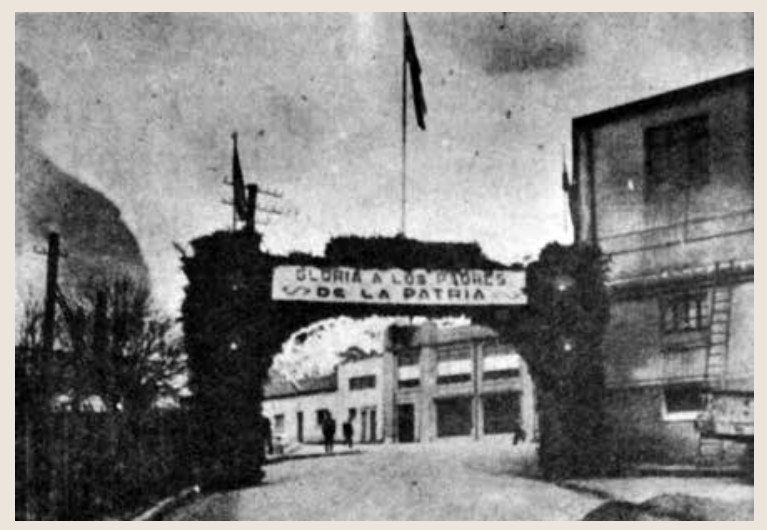

Figura 3. "Uno de los arcos que adornaban la entrada de la población de Lota Alto" (La Opinión, 1945, octubre, p. 5).

La preocupación principal de la compañía y sus adláteres era instaurar al interior de la ciudadela modelo un tipo de celebración donde las personas se divertían sin los excesos provocados por la ingesta de alcohol, como señaló el administrador de la compañía acerca de las celebraciones de septiembre de 1924, las que a su juicio "probaron las ventajas de este temperamento", puesto que se suspendieron los trabajos el 17 para volver el 20 de septiembre:

Di permiso para instalar ramadas, y pude ver a las gentes divirtiéndose y bailando sin beber otra cosa que limonada y bilz; ;se consumieron en dos días cerca de 40 mil botellas de gaseosa! El sábado se salió al trabajo como de costumbre, sin tener que lamentar hechos delictuosos, sin tener que anotar fallas y, sobre todo, sin tener gentes trabajando de mala gana a causa de estar "con el cuerpo malo".

Pensaba en la grandeza moral de nuestros obreros tan fáciles de renunciar a sus vicios, cuando de por medio está dar muestras de la cultura enorme que han alcanzado (El Sur, 1925, enero 27).

Años después, el discurso emanado desde la compañía continuaba siendo el mismo y la festividad de septiembre se usaba como un medio para disciplinar y profundizar los valores patrióticos que el obrero debería expresar en su trabajo, "con este decidido apoyo patronal, el espíritu cívico de obreros y empleados es encauzado hacia hermosas manifestaciones que constituyen lecciones prácticas de patriotismo y cultura" (El Sur, 1928, septiembre 18). 
Esta idea se materializa en una editorial de La Opinión, el órgano oficial de la compañía minera de Lota, en cuyas páginas se llamaba metódicamente a profundizar el patriotismo mediante una nueva actitud de compromiso con el trabajo, el aporte esencial del trabajador carbonífero para engrandecimiento de su patria. Como señalaba el citado periódico:

En los días de fiestas, muy difícil estará para las personas que llegan a Lota, distinguir a un obrero minero de un empleado. Pasaron los tiempos de las ojotas, de las fajas de colores al cinto y del sombrero agüainado, como decíamos antaño, a los sombreros plegados con hilo de saco. El ambiente actual es de plena civilización, la modalidad del minero ha cambiado por completo, antes era un ser despreciable por su incultura, ahora es un operario correcto, que ha extirpado de su vocabulario las palabras indecorosas, viste bien, frecuenta los salones sociales y sabe comportarse como un caballero en el sitio que se presente ${ }^{4}$.

Durante el periodo estudiado, las fiestas patrias se estimulaban con la realización de concursos de afiches promocionales de estas festividades y literarios, cuyos resultados se usaban como prólogo a las fiestas y premiaban con elogios a la reina de la primavera ${ }^{5}$.

La propuesta central era una celebración apegada al modelo de orden, carentes de alcohol y riñas, donde los trabajadores se entretuvieran sanamente, pudiendo volver al trabajo sin problemas de embriaguez y ausentismo. Por cierto, el ideal de la empresa no siempre se concretó y la realidad del mundo popular y su sociabilidad se manifestó con libertad en los extramuros o en los espacios clandestinos al interior de la empresa.

\section{CONCLUSIÓN}

Si bien es cierto toda forma de trabajo asalariado resulta un tipo más de trabajo dependiente (Moulier-Boutang, 2006), las características que revistió el laborar en la Compañía Carbonífera de Lota presentaban importantes niveles de cooptación de los trabajadores mediante condiciones de vida relativamente buenas para el contexto social de la época. La compañía entregaba al interior de la ciudadela modelo una importante cantidad de

${ }^{4}$ La Opinión, Lota Alto, 15 de junio de 1930.

${ }^{5}$ La Opinión, Lota Alto, noviembre de 1945. 
beneficios a cambio del irrestricto respeto a las normas establecidas unilateralmente y orientadas en función de la productividad.

En el control ejercido sobre los trabajadores de la compañía el Departamento de Bienestar jugó un papel preponderante, dado que entre la multiplicidad de sus funciones también consideró la regulación y organización de las fiestas al interior de Lota Alto. Los ejemplos se multiplican en las fiestas del carnaval o chaya, en las fiestas religiosas y en las fiestas del Estado nacional, que implicaban un problema y una oportunidad para ejercer el control, principalmente porque su celebración podía regularse, pero no prohibirse, en tanto eran estimuladas desde el aparato estatal. Pero también fueron una oportunidad debido a que las fiestas permitían cohesionar a los trabajadores y la comunidad de Lota Alto en torno a los ideales patrios que se imbricaban con los objetivos de la compañía, buscando buenos trabajadores, responsables y dedicados en su trabajo, conjunto de tareas con que se suponía contribuían al engrandecimiento del país.

De esta manera, no resulta extraño constatar cómo se intentó regular la sociabilidad festiva de los trabajadores de la compañía, en especial en las festividades del dieciocho de septiembre, las que por su alta raigambre popular eran las más difíciles de disciplinar y controlar. No obstante, como resaltó desde la literatura Carlos Droguett, se produjo la paradoja de orden para los trabajadores y exceso para los dueños, cuando narró con filosas letras su percepción de la realidad laboral en Chile hacia mediado del siglo $\mathrm{XX}$, destacando la contraposición de ideas entre una historia "ordenada; encuadernada y empastada" que olvidaba a los trabajadores expuestos al trabajo duro y la muerte eventual "en los bajíos de Lota y Coronel, cuarenta millas mar adentro, bajo el castillo de los Cousiño y las fiestas embriagadas, sin condones de los Cousiño, algunos miles de rotos descamisados" (1975, p. 238). Por cierto, esta paradoja del control parece no haber sido privativa de Lota en el periodo estudiado.

\section{REFERENCIAS}

Absi, P. (2009). Los ministros del diablo. El trabajo y sus representaciones en las minas de Potosí. La Paz: Institut de recherche pour le développement en Bolivie - IFEA, 69-77.

Astorquiza, O. y Galleguillos, O. (1951). Cien años del carbón de Lota, 18521952. Santiago: Compañía Carbonífera e Industrial de Lota.

Barrán, J. P. Historia de la sensibilidad en el Uruguay. La cultura bárbara (18601900). Capítulo I. Montevideo: Ed. De la Banda Oriental. 
Benjamin, W. Denkbilder (2011). Epifanías en viaje. Buenos Aires: El Cuenco de Plata.

Bercé, Y.-M. (1976). Fête et révolte. Des mentalités populaires du XVIe au XVIIIe siècle. Paris: Hachette Literatures.

Cuevas, F. (2006). "Ferrocarril, carbón y paternalismo industrial en Barruelo de Santullan”. Actas IV Congreso de historia ferroviaria, Málaga.

DaMatta, R. (2002). Carnavales, malandros y héroes. Hacia una sociología del dilema brasileño. Ciudad de México: Fondo de Cultura Económica.

Droguett, C. (1975). Matar a los viejos. Santiago: Lom.

El Sur (1923, agosto 7). "Una satisfactoria solución a la huelga de los obreros de Schwager".

El Sur (1930, mayo 21). "En la industria del carbón”.

El Sur (1930, mayo 28). "Un gran impulso de progreso se advierte en el establecimiento minero de Lota".

El Sur de Concepción (1921, febrero 11). "Departamentos de Bienestar”.

El Sur de Concepción (1924, mayo 4). "Ayer estuvieron paralizados los trabajos".

El Sur de Concepción (1925, enero 27). "Por las tierras del carbón”.

El Sur de Concepción (1925, septiembre 25). "Fiestas Patrias".

El Sur de Concepción (1926, septiembre 16). "Programa de celebración de fiestas patrias".

El Sur de Concepción (1928, septiembre 18). "Festividades públicas".

El Sur de Concepción (1930, mayo 21). "En la industria del carbón”.

Empresa Nacional del Carbón (1934, abril 6). "Carta anexa a prontuario de Isaías Inostroza”. Archivo Empresa Nacional del Carbón (AENACAR), Prontuario 18, Lota: ENACAR.

Empresa Nacional del Carbón (1936, febrero 21). "Hoja de servicios Isaías Inostroza”. Archivo Empresa Nacional del Carbón (AENACAR), Prontuario 18 , s/f. Lota: ENACAR.

Empresa Nacional del Carbón (1936, febrero 21). "Hoja de servicios de Isaías Inostroza". Archivo Empresa Nacional del Carbón (AENACAR), Prontuario 18 , s/f. Lota: ENACAR.

Empresa Nacional del Carbón (1957, noviembre 28). Solicitud de informe la conducta de Segundo Monsalve Monsalve. Minas Schwager. Archivo Empresa Nacional del Carbón (AENACAR), Prontuario 18. Lota: ENACAR.

Foucault, M. (1989). Vigilar y castigar. Buenos Aires: Siglo XXI.

García, J. (2013, julio 6). "Hernán Rivera Letelier: 'En la pampa se hacían las mejores fiestas de Chile". Entrevista. La Tercera.

Godoy Orellana, M. (2009). Fiesta, carnaval y disciplinamiento cultural en el Norte chico, 1840-1900. Tesis para optar al grado de Doctor en Historia. Santiago: Universidad de Chile.

Hidalgo, J. y Castro, N. (1999). "Rebelión y carnaval. Ingaguasi (San Pedro de Atacama) 1775-1777”. Estudios Atacameños, 17, 61-90. 
La Opinión. Lota Alto (1945, octubre). "La celebración de las Fiestas Patrias", p. 5.

La Opinión. Lota Alto, febrero de 1945.

La Opinión. Lota, 18 de septiembre de 1928, p. 2.

Labori, M. y Tetier, J. M. (1995). Le féodalisme industriel. Patronat textile et révolte ouvrière de $1^{\circ}$ de mai 1891 à Fourmies. Cahors: Sides.

López, P. (2010). Del campo a la fábrica. Vida y trabajo en una colonia industrial. Madrid: Ed. Catarata.

Ministerio de Asuntos Extranjeros de Francia, Chile, Correspondencia comercial (1884, diciembre 26). "Notas sobre las minas de carbón y de los establecimientos industriales de Lota". Archives Diplomátiques de La Courneuve Vol. 13, Fs. 114 V. Santiago.

Moulier-Boutang, Y. (2006). De la esclavitud al trabajo asalariado. Economía histórica del trabajo asalariado embridado. Madrid: Akal.

Norambuena, C. (Ed.) (1997) ¿Faltan o sobran brazos? Migraciones internas y fronterizas (1850-1930). Santiago: Ed. Universidad de Santiago de Chile.

Oliver, P. (2005) "El concepto de control social en la Historia Social: estructuración del orden y respuestas al desorden". Revista de Historia Social, 51.

Oro Negro. Periódico independiente al servicio de la zona carbonifera. Coronel (1949, septiembre 3).

Pérez Álvarez, G. (2013). “Juego, resistencia y cultura obrera en la Patagonia Argentina: el fútbol ante contextos represivos". Nuevo Mundo Mundos Nuevos. [En línea], Questions du temps présent. URL: http://nuevomundo.revues.org/65161 ; DOI: 10.4000/nuevomundo.65161

Rodríguez, Z. (1875). Diccionarios de chilenismo. Santiago: Imp. El Independiente.

Scott, J. (2000). Los dominados y el arte de la resistencia. México: Era.

Scranton, Ph. (1984). "Variety of paternalism: industrial structure and the social relations of production in American textiles". American Quarterly, 36/2, The John Hopkins University Press, 235-236.

Sierra Álvarez, J. (1990). El obrero soñado: Ensayo sobre el paternalismo industrial: Asturias, 1860-1917. Madrid: Ed. Siglo XXI.

Thompson, E. (1984). Tradición, revuelta y conciencia de clase. Estudios sobre la crisis de la sociedad industrial. Barcelona: Editorial Crítica.

Uría, J. (1995). "Cultura popular tradicional y disciplinas de trabajo industrial. Asturias, 1880-1914”, Historia Social, 23, 60.

Venegas, H. (2013). "Paternalismo industrial y control social. Las experiencias disciplinadoras en la minería del carbón en Chile. Lota y Coronel, primera mitad del siglo XIX". Les Cahiers ALHIM, 12/27. 